\title{
Analysis of psychotropic drug advertising
}

\author{
John Quinn, Marie Nangle and Patricia R. Casey
}

\begin{abstract}
The use of metaphors as the main marketing strategy in psychotropic drug advertising in joumals and the quality of information provided in these advertisements has been crticised. We investigated marketing strategles and information provision in advertisements appearing in three different poychiatric joumals. The majortty of advertisements in two of the joumals used metaphors as their main marketing strategy. The level of prescribing information varied between joumals. Our findings suggest that improvements are needed in psychotropic drug advertising in joumals.
\end{abstract}

Physicians often deny the relative importance of commercial sources in influencing their prescribing (Avorn et al, 1982) but studies have shown that drug advertising does influence prescribing patterns (Hemminki, 1975). Indeed pharmaceutical companies spend a substantial percentage of their sales income on promotion which includes advertising in journals (Avorn et al, 1982).

Prescribing by physicians should be based on logic which would involve the analysis of the benefits, safety and cost of medicines. However, advertisers often use symbolic images (metaphors) in journal advertisements to circumvent logical argument when trying to persuade doctors to make choices in prescribing (Goldman \& Montagne, 1986; Owen, 1992; Scott \& Ferner, 1994). This also applies to psychotropic drug advertisements; studies have shown that advertising in this area tends to be more unscientific and less informative than other types of drug advertisements (Hemminki, 1975; Lion et al, 1979) and commonly to use metaphors as their main marketing strategy (Goldman \& Montagne, 1986; Riska \& Hagglund, 1991).

In view of this, we examined psychotropic drug advertisements in three psychiatric journals in three different countries to determine, in each advertisement, the main marketing strategy used and the presence/absence of prescribing information.

\section{The study}

We analysed all psychotropic drug advertisements in the American Journal of Psychiatry
(AJP), the British Journal of Psychiatry (BJP) and the Irish Journal of Psychological Medicine (IJP) between February 1988 and September 1995 inclusive (February 1988 coincided with the first publication of the latter journal).

Analysis involved determining the main method of advertising used in each advertisement in a similar manner to that described by Riska \& Hagglund (1991). If no category was dominant, the category 'mixed' was applied. We also determined the presence/absence of prescribing information (uses, dosage, contraindications, etc.) and noted differences between the three journals in terms of the above items.

Drugs were allocated to five categories: antipsychotic, antidepressant, hypnotic, anxiolytic and others (includes lithium and drugs for use in obsessive-compulsive disorder).

\section{Findings}

A total of 2045 advertisements for psychotropic drugs were analysed in the period under study; 978 appeared in the AJP, 742 in the BJP and 325 in the IJP. Table 1 shows that advertisements for antidepressants constituted the largest category in all three journals, with antipsychotic advertisements being the second largest.

Table 2 reveals that the majority of advertisements in both the BJP and IJP used metaphors as the main method of advertising, in contrast to the AJP where the 'mixed category' was the most used. The use of metaphor in the AJP was less than the BJP or IJP $(P<0.001)$. Metaphors most commonly used in antidepressant advertisements were sunshine/cloud, light/darkness and black/white. Similar metaphors were used in antipsychotic advertisements, with storm/

Table 1. Drug categories in each journal

\begin{tabular}{llcc}
\hline Drug category & \multicolumn{4}{l}{ AJP $(n=978)$} & BJP $(n=742)$ & IJP $(n=325)$ \\
\hline Antidepressant & $411(42 \%)$ & $405(54.6 \%)$ & $146(44.9 \%)$ \\
Antipsychotic & $302(30.9 \%)$ & $301(40.6 \%)$ & $83(25.5 \%)$ \\
Anxiolytic & $161(16.5 \%)$ & $6(0.8 \%)$ & $52(16.0 \%)$ \\
Hypnotic & $44(4.5 \%)$ & $27(3.6 \%)$ & $25(7.7 \%)$ \\
Others & $60(6.1 \%)$ & $3(0.4 \%)$ & $19(5.9 \%)$ \\
\hline
\end{tabular}


Table 2. Main methods of advertising

\begin{tabular}{lccc}
\hline $\begin{array}{l}\text { Advertising } \\
\text { method }\end{array}$ & $\begin{array}{l}\text { AJP } \\
(n=978)\end{array}$ & $\begin{array}{l}\text { BJP } \\
(n=742)\end{array}$ & $\begin{array}{l}\text { JPP } \\
(n=325)\end{array}$ \\
\hline Metaphor & $299(30.6 \%)$ & $451(60.8 \%)$ & $196(60.3 \%)$ \\
Patient & $253(25.9 \%)$ & $136(18.3 \%)$ & $18(5.5 \%)$ \\
Statement & $43(4.4 \%)$ & $40(5.4 \%)$ & $82(25.2 \%)$ \\
$\begin{array}{l}\text { Physiological } \\
\text { phenomenon }\end{array}$ & & $10(1.3 \%)$ & $2(0.6 \%)$ \\
Drug package & $66(6.8 \%)$ & & $9(2.8 \%)$ \\
$\begin{array}{l}\text { Diagram } \\
\text { Mixed categories }\end{array}$ & $\begin{array}{l}1(0.1 \%) \\
\text { 316(32.4\%) }\end{array}$ & $105(14.2 \%)$ & $8(5.5 \%)$ \\
\hline
\end{tabular}

calm and metaphors suggesting instability/ stability also being common.

Table 3 shows prescribing information content in advertisements. More than $80 \%$ of advertisements in the BJP and AJP contained prescribing information. The provision of such information in the IJP advertisements was less than either of the other journals $(P<0.0001)$.

\section{Comment}

Goldman \& Montagne (1986) described how advertisers seek to identify their product with an image. An advertisement for an antidepressant may contrast darkness (a metaphor for depression) with sunlight (a metaphor for recovery). Metaphorically, therapeutic progress has occurred through ingestion of the drug - the depression has lifted, a return to health being signified by sunlight. In our study, over $60 \%$ of advertisements in the BJP and IJP used metaphors as the main method of advertising, significantly more than the usage of metaphor in the AJP. Similar results to the IJP and BJP were found in Danish and Finnish journals (Riska \& Hagglund, 1991).

This form of advertising is not scientific (Avorn et al, 1982; Kleinman \& Cohen, 1991; Ferner \& Scott, 1994). Metaphors are being used to symbolise mental illness, health and the therapeutic action of the drug. Depression for example is reduced to a simple single entity (darkness) for which there is only one treatment (medication) and with medication health (sunlight) will be restored. The possibility of multiple causes for such illness and variations in individual presentation is rendered inconsequential (Goldman \& Montagne, 1986). In this type of

Table 3. Prescribing information in advertisements

\begin{tabular}{lll}
\hline & \multicolumn{2}{l}{ Prescribing information } \\
\cline { 2 - 3 } Joumal & Yes & No \\
\hline AJP $(n=978)$ & $840(85.9 \%)$ & $138(14.1 \%)$ \\
BJP $(n=742)$ & $601(81 \%)$ & $141(19 \%)$ \\
IJP $(n=325)$ & $124(38.2 \%)$ & $201(61.8 \%)$ \\
\hline
\end{tabular}

framework mental illness is being treated like physical disease (Seidenberg, 1971). No account is taken of alternative therapeutic strategies (Kleinman \& Cohen, 1991) or that a substantial percentage of individuals do not respond to medication. Drug companies may use this type of advertising, especially in smaller highly competitive markets, to expand their market shares (Goldman \& Montagne, 1986). This may in part explain the high prevalence of the use of metaphors in the BJP and IJP. Regulation of drug advertising itself also plays a role (Scott \& Ferner, 1994).

The quality of drug information in advertisements varies widely between countries (Herxheimer et al, 1993). In our study, advertisements in the IJP provided significantly less prescribing information than those in the AJP or BJP. It is true that many advertisements not containing such information are simply 'reminder advertisements'. However, it is important that all advertisements contain adequate prescribing information, as drug advertisements can have a great influence on prescribing habits, sometimes even more than scientific literature (Avorn et al, 1982) and there is a possibility that doctors might prescribe drugs based on advertising alone (Herxheimer et al, 1993). It is noteworthy that all advertisements in the last issue of the IJP under study (September, 1995) provided prescribing information.

Our findings suggest that improvements are needed in psychotropic drug advertising, in terms of strategies used to advertise and information provision. Drug advertisers should avoid using unscientific metaphors as their main marketing strategy and should concentrate on providing adequate prescribing information on the psychotropic drug being advertised. Regulatory agencies controlling drug advertising in each country are important in this aspect (Lexchin, 1987). Psychiatrists should be aware of marketing strategies used by drug companies (Scott \& Ferner, 1994). As Dixon (1993) states: "a constructively critical approach towards advertisements is an important learned skill that should be an essential part of undergraduate, postgraduate and continuing education."

\section{Acknowledgements}

Many thanks to Dr Mary Codd, Consultant Epidemiologist, for her advice, and to Claire Martin for her help.

\section{References}

Avorn, J., Chen, M. \& HARTLEY, R. (1982) Scientific versus commercial sources of influence on the prescribing behaviour of physicians. American Journal of Medicine, 73, 4-8. 
Dixon, T. (1993) Pharmaceutical advertising, information or influence? Canadian Family Physician, 39, 1298-1300.

FERNER, R. \& SCOTT, D. (1994) Whatalotwegot - the messages in drug advertisements. British Medical Joumal, s09, 1734-1736.

Goldman, R. \& Montagne, M. (1986) Marketing 'mind mechanics': decoding antidepressant drug advertisements. Social Science and Medicine, 22. 1047-1058.

Hemmink, E. (1975) Review of literature on the factors affecting drug prescribing. Social Science and Medicine, 9. 111-115.

HERXHEIMER, A., LUNDBORG, C. \& Westerholm, B. (1993) Advertisements for medicines in leading medical journals in 18 countries: a 12 month survey of information content and standards. International Journal of Health Services, 23, 161-172.

KLEINMAN, D. \& COHEN, L. (1991) The decontextualisation of mental illness: the portrayal of work in psychiatric drug advertisements. Social Science and Medicine, 32. 867-874.

LEXCHIN, J. (1987) Pharmaceutical promotion in Canada: convince them or confuse them. International Journal of Health Services, 17, 77-89.
Lion, J., REgan, B., TAYLOR, R., et al (1979) Psychiatrists' opinions of psychotropic drug advertisements. Social Science and Medicine, 18A, 123-125.

OWEN, J. (1992) Images used to sell psychotropic drugs. Psychiatric Bulletin, 16, 25-26.

RisKA, E. \& HAGGLUND, U. (1991) Advertising for psychotropic drugs in the Nordic countries: metaphors, gender and life situations. Social Science and Medicine, 32, 465-471.

SCOTT, D. \& FERNER, R. (1994) The strategy of desire' and rational prescribing. British Journal of Clinical Pharmacology. 37, 217-219.

SEIDENBERG, R. (1971) Drug advertising and perception of mental illness. Mental Hygiene, 55, 21-31.

*John Quinn, Special Lecturer in Psychiatry. Marie Nangle, Medical Student and Patricia R. Casey, Professor of Psychiatry, Mater Misericordiae Hospital, Dublin 7, Ireland

*Correspondence

\section{$£$ Seminars in Clinical Psychopharmacology Edited by David J. King}

Psychopharmacology is a key both to the understanding of the biological basis of severe mental illness and to the rational use of drugs in clinical psychiatry. This book is an excellent introduction to an ever-expanding and fascinating subject, linking relevant basic neuropharmacology to clinical practice. It aims to bridge the gap between the theoretical basis for the mode of action of psychotropic drugs and guidance on their clinical use, and should increase interest in and understanding of the drugs widely used in clinical practice. $£ 20.00,544 p p ., 1995$, ISBN 0902241737

Available from bookshops and from the Publications Department, Royal College of Psychiatrists, 17 Belgrave Square, London SW1X 8PG (Tel. 01712352351 extension 146)

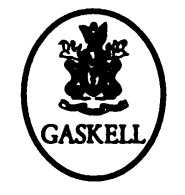

